\title{
A study on prevalence and associations of non-robustness in older adults aged 65 years and above attending a general practitioner clinic in Ang Mo Kio
}

\author{
Junjie $\underline{A w^{1}}$, MBBS, FCFP, Eng Sing $\underline{L e}^{2}, \mathrm{MBChB}, \mathrm{PhD}$, Grace $\underline{C h i a n g^{3}}$, MBBS, FCFP, Boon Yeow $\underline{\operatorname{Tan}}^{3}$, MBBS, FCPP
}

\section{INTRODUCTION}

In Singapore's rapidly ageing society, the proportion of older adults aged above 65 years increased by $6 \%$ annually between 2015 and 2017. ${ }^{(1)}$ Frailty in older adults is associated with adverse health outcomes such as loss of independence, institutionalisation and mortality, (2) thus increasing healthcare needs and costs. As pre-frail individuals are more likely to return to robustness, while frail individuals are more likely to remain frail, ${ }^{(3,4)}$ we should identify pre-frail individuals for timely interventions to prevent progression to frailty. Simultaneously, we need to plan and provide for the healthcare and socioeconomic needs of frail older adults.

As our ageing population is largely cared for by primary healthcare physicians, the latter are well-positioned to identify frailty syndrome and its accompanying medical and social issues. However, the prevalence of frailty and pre-frailty among older adults seeking medical consultations in general practice clinics in Singapore has not been studied. Prior local data was from population or hospital-based studies, ${ }^{(5-7)}$ while other Asian studies were conducted in low-income countries or rural settings with limited generalisability to Singapore. ${ }^{(8,9)}$ In this study, we aimed to assess the prevalence of frailty and pre-frailty and evaluate factors associated with them among older adults who visited a general practice clinic in a residential estate in Singapore.

\section{METHODS}

This was a cross-sectional observational study of participants aged 65 years and above who attended the Frontier Medical Associates (Ang Mo Kio) general practice clinic between October 2018 and January 2019. Individuals were excluded if they were unable to give informed consent, had a speech or hearing impairment that impaired their ability to respond to a telephone interview, or required emergency care in a hospital.

Eligible participants were enrolled after giving written informed consent and contacted by an interviewer via telephone within one week after enrolment. The interviewer was blinded to the participant's past history and had no prior clinical contact. There were two interviewers who both received standardised training on conducting the telephone interviews. Telephone interviews were conducted in English, Mandarin or Hokkien. Enrolled participants who were uncontactable by telephone on two separate occasions within a week were considered to have withdrawn from the study. The study abided by the Declaration of Helsinki, and the protocol was approved by the St Luke's Hospital Institutional Review Board (IRB-01-2018-07-12).

Participants' demographic and medical comorbidity data were obtained through interviewer-administered questionnaires. Missing data was filled in by cross-checking the medical records of the participants as much as possible. Information collected included marital status, educational level, home ownership and type, employment status, and whether they stayed with their family or had a domestic helper.

In addition to documenting medical conditions, chronic disease burden was determined using the number of chronic medications $(\geq 5)$ as a surrogate marker. ${ }^{(10-13)}$ Chronic pain was defined as pain that occurred at least four days in a week for three or more months. ${ }^{(14)}$ Basic activities of daily living (bADL) dependence was present if the patient had difficulty or required assistance in any of the six bADLs, namely bathing, toileting, dressing, eating, transferring and mobility.

The primary outcome was frailty and the secondary outcome was non-robustness (combining the frail and pre-frail groups). Although there is no consensus on a gold standard for measuring frailty, the most frequently used assessment tools are the Comprehensive Geriatric Assessment and Fried Frailty Phenotype. ${ }^{(15-18)}$ These tools are cumbersome and timeconsuming, thus limiting their effective use in a busy primary care clinic. Instead, we used the five-point FRAIL (fatigue, resistance, ambulation, illnesses and loss of weight) scale, developed by the International Association of Nutrition and Aging, ${ }^{(19)}$ to determine robust, pre-frail and frail states. This scale assesses the domains of fatigue, resistance, ambulation, illnesses and weight loss, with one point for each domain. Participants were then classified as robust (score 0), pre-frail (score 1-2) or frail (score 3-5). The FRAIL scale is widely validated in Asia, the United States, Europe and South America. ${ }^{(20-24)}$ Compared to other frailty instruments such as the Frailty Index, ${ }^{(25)}$ Cardiovascular Health Study frailty scale, ${ }^{(26)}$ and Study of Osteoporotic Fractures index, ${ }^{(27)}$ the FRAIL scale had the strongest predictive validity for new disability and mortality. ${ }^{(28)}$ Locally, the FRAIL scale predicted in-hospital adverse outcomes and was the best predictor of mortality in a local tertiary hospital when compared with the Tilburg Frailty Indicator and Clinical

${ }^{1}$ Frontier Medical Associates (Ang Mo Kio), ${ }^{2}$ National Healthcare Group Polyclinics, ${ }^{3}$ St Luke's Hospital, Singapore

Correspondence: Dr Junjie Aw, Associate Consultant, SingHealth Community Hospitals -Outram Community Hospital, 10 Hospital Blvd, Singapore 168582. aw.junjie@singhealth.com.sg 
Frailty Scale, using the Frailty Index as the gold standard. ${ }^{(7)}$ Scoring of the FRAIL scale can be done quickly without need of expertise knowledge, physical measurement or special equipment, making it ideal for busy healthcare providers.

A sample size of 91 was required for a cross-sectional study to detect frailty prevalence, based on a precision error of $5 \%$, Type 1 error of $5 \%$, and an expected prevalence of $6.2 \%$ obtained from the local population-based HOPE study. ${ }^{(5)}$

Categorical variables were presented as proportions, and continuous variables were summarised as median with interquartile range (25th-75th percentile). Pearson chi-square test or Fisher's exact test was used to compare categorical variables and Mann-Whitney $U$ test to compare ranks for non-normally distributed continuous variables. Binary logistic regression analysis (stepwise method) was used to calculate odds ratio (OR) and 95\% confidence interval (Cl) for factors associated with outcomes. Covariates were chosen if $p$-values were $\leq 0.05$ on bivariate analysis. All analyses were two-tailed and $p<0.05$ was considered statistically significant. Statistical analysis was performed using IBM SPSS Statistics version 25.0 (IBM Corp, Armonk, NY, USA).

\section{RESULTS}

A total of 241 participants were assessed for eligibility during the recruitment period between October 2018 and January 2019. 145 participants were enrolled after excluding 96, of whom ten did not meet the eligibility criteria and 86 did not consent to the study. 97 participants completed the telephone survey.

Table I shows the sociodemographic and clinical characteristics of the cohort. The median age was 71.7 years, and $53.6 \%$ were female. Most of the participants (74.2\%) had a living spouse: $21(21.6 \%)$ were widowed, while $3(3.1 \%)$ were single. Half the participants had received either primary $(n=26,26.8 \%)$ or secondary school education ( $\mathrm{n}=28,28.9 \%)$, while 29 (29.9\%) participants did not have any formal education. Common comorbid conditions were hypertension, hyperlipidaemia, diabetes mellitus, arthritis and osteoporosis. Few participants had dementia ( $n=2,2.1 \%)$; mental illness $(n=4,4.1 \%)$; depression $(\mathrm{n}=3,3.1 \%)$; cardiac disease such as a previous heart attack $(n=6,6.2 \%)$, angina $(n=3,3.1 \%)$ and arrhythmia $(n=3,3.1 \%)$; chronic kidney disease $(n=5,5.2 \%)$; and previous stroke $(n=5$, $5.2 \%)$. None had chronic liver disease or Parkinson's disease.

Frailty was present in $10(11.8 \%)$ participants, while $33(38.8 \%)$ were pre-frail and $42(49.4 \%)$ were robust. Weight loss data was missing for $12(12.4 \%)$ participants who were uncertain of their weight change. In order to evaluate risk factors for outcomes, we considered that participants would likely notice a clinically significant weight loss of $5 \%$ or more. Hence, missing weight loss data was imputed as 'no weight loss'.

Comparing the frail and the non-frail on bivariate analysis (Table II), those who were categorised as frail were more likely to be older (OR 1.12, 95\% Cl 1.03-1.23; $\mathrm{p}=0.01$ ). They were less likely to have a living spouse (OR $0.11,95 \% \mathrm{Cl}$ $0.03-0.45 ; \mathrm{p}=0.002)$, stay with family (OR $0.11,95 \% \mathrm{Cl} 0.03-$ $0.51 ; \mathrm{p}=0.005$ ) or own their homes (OR 0.05, 95\% Cl 0.01-0.30;
Table I. Sociodemographic and clinical characteristics of elderly individuals in the study $(n=97)$.

\begin{tabular}{|ll|}
\hline Characteristic & No. (\%) \\
\hline Age* $(\mathbf{y r})$ & $71.7(68.9-78.5)$ \\
\hline Male gender & $45(46.4)$ \\
\hline Ethnicity & \\
\hline Chinese & $85(87.6)$ \\
\hline Malay & $5(5.2)$ \\
\hline Indian & $5(5.2)$ \\
\hline Others & $2(2.1)$ \\
\hline Living married spouse & $72(74.2)$ \\
\hline Weight* (kg) & $62(53-69)$ \\
\hline Body mass index* (kg/m $\left.{ }^{2}\right)$ & $23.6(21.8-26.0)$ \\
\hline Formal education ${ }^{\dagger}$ & $68(70.1)$ \\
\hline House ownership & $91(93.8)$ \\
\hline Type of home owned & \\
\hline Public & $69(71.1)$ \\
\hline Private & $22(22.7)$ \\
\hline Stays with family & $86(88.7)$ \\
\hline Domestic helper & $25(25.8)$ \\
\hline Currently employed & $24(24.7)$ \\
\hline$\geq 5$ chronic medications & $20(20.6)$ \\
\hline Chronic pain ${ }^{*}$ & $33(34.0)$ \\
\hline bADL restriction & $7(7.2)$ \\
\hline Hypertension & $76(78.4)$ \\
\hline Hyperlipidemia & $78(80.4)$ \\
\hline Diabetes mellitus & $20(20.6)$ \\
\hline Arthritis & $18(18.6)$ \\
\hline Osteoporosis & $22(22.7)$ \\
\hline & \\
\hline & \\
\hline
\end{tabular}

*Data presented as median (25th-75th percentile). $†$ Defined as primary school and beyond. $\neq$ Defined as pain that occurred $\geq 4$ days in a week for $\geq 3$ months. bADL: basic activities of daily living (bathing, toileting, dressing, eating, transferring and mobility)

$\mathrm{p}=0.001)$. Chronic pain (OR 5.47, 95\% Cl 1.31-22.84; $\mathrm{p}=0.02)$, bADL dependence (OR 22.13,95\% Cl 3.85-127.11; $\mathrm{p}=0.001$ ) and depression (OR 21.50, 95\% Cl 1.75-263.87; $p=0.02$ ) were more frequent in the frail older adults.

Table III compares factors associated with non-robustness (both frail and pre-frail). Non-robust older adults were less likely to have a living spouse (OR $0.24,95 \% \mathrm{Cl} 0.08-0.67 ; \mathrm{p}=0.007$ ) and formal education (OR 0.34, 95\% Cl 0.13-0.84; $\mathrm{p}=0.02$ ), but more likely to be taking five or more chronic medications (OR 3.82, 95\% Cl 1.26-11.59; $\mathrm{p}=0.018$ ) and have chronic pain (OR 5.21, 95\% Cl 2.03-13.38; $p=0.001$ ).

Multivariable analysis of factors associated with nonrobustness (Table IV), taking into account marital status, formal education, chronic medication burden and chronic pain, found that chronic pain and absence of a living spouse were independently associated with non-robustness. Sensitivity analysis of the scenario where missing values for weight loss data were imputed as having weight loss (instead of having none) found that the association between non-robustness and chronic pain persisted (adjusted OR 3.10, 95\% Cl 1.17-8.27; $p=0.02$ ), while the association with living spouse was lost. 
Table II. Comparison of frail and non-frail elderly.

\begin{tabular}{|c|c|c|c|}
\hline \multirow[t]{2}{*}{ Characteristic } & \multicolumn{2}{|c|}{ No. (\%) } & \multirow[t]{2}{*}{ p-value } \\
\hline & Non-frail $(n=87)$ & Frail $(n=10)$ & \\
\hline Age* $^{*}(\mathrm{yr})$ & $71.4(68.8-77.9)$ & $80.6(71.5-88.7)$ & 0.04 \\
\hline Male gender & $41(47.1)$ & $4(40.0)$ & 0.75 \\
\hline $\begin{array}{l}\text { Living married } \\
\text { spouse }\end{array}$ & $69(80.2)^{+}$ & $3(30.0)$ & 0.002 \\
\hline $\begin{array}{l}\text { Body mass index* } \\
\left(\mathrm{kg} / \mathrm{m}^{2}\right)\end{array}$ & $23.6(21.7-26.1)$ & $23.8(21.8-26.0)$ & 0.77 \\
\hline Formal education & $63(72.4)$ & $5(50.0)$ & 0.16 \\
\hline Home ownership & $83(95.4)$ & $6(60.0)$ & $<0.001$ \\
\hline Stays with family & $80(93.0)^{\dagger}$ & $6(60.0)$ & 0.01 \\
\hline Domestic helper & $21(25.0)^{+}$ & $4(40.0)$ & 0.45 \\
\hline $\begin{array}{l}\text { Currently } \\
\text { employed }\end{array}$ & $23(26.4)$ & $1(10.0)$ & 0.25 \\
\hline $\begin{array}{l}\geq 5 \text { chronic } \\
\text { medications }\end{array}$ & $17(20.0)^{+}$ & $4(40.0)$ & 0.22 \\
\hline Chronic pain & $26(29.9)$ & $7(70.0)$ & 0.03 \\
\hline Depression & $1(1.1)$ & $2(20.0)$ & 0.03 \\
\hline bADL restriction & $3(3.5)^{+}$ & $4(44.4)$ & 0.001 \\
\hline
\end{tabular}

Categorical variables expressed as no. (\%) were compared using Pearson chi-square test or Fisher's exact test, as appropriate. *Continuous variables expressed as median (interquartile range 25 th-75th percentile) were compared using Mann-Whitney $U$ test. †Percentages were calculated based on available values. bADL: basic activities of daily living (bathing, toileting, dressing, eating, transferring and mobility)

Table III. Comparison of robust and non-robust (frail and pre-frail) elderly.

\begin{tabular}{|c|c|c|c|}
\hline \multirow[t]{2}{*}{ Characteristic } & \multicolumn{2}{|c|}{ No. (\%) } & \multirow[t]{2}{*}{ p-value } \\
\hline & Non-robust $(n=49)$ & Robust $(n=48)$ & \\
\hline $\mathrm{Age}^{*}(\mathrm{yr})$ & $72.5(69.1-82.4)$ & $71.5(68.9-76.0)$ & 0.11 \\
\hline Male & $18(36.7)$ & $27(56.3)$ & 0.06 \\
\hline $\begin{array}{l}\text { Living married } \\
\text { spouse }\end{array}$ & $30(62.5)$ & $42(87.5)$ & 0.005 \\
\hline $\begin{array}{l}\text { Body mass } \\
\text { index }{ }^{*}\left(\mathrm{~kg} / \mathrm{m}^{2}\right)\end{array}$ & $23.5(21.8-26.5)$ & 23.7 (21.8-25.7) & 0.98 \\
\hline $\begin{array}{l}\text { Formal } \\
\text { education }\end{array}$ & $29(59.2)$ & $39(81.3)$ & 0.02 \\
\hline $\begin{array}{l}\text { Home } \\
\text { ownership }\end{array}$ & $43(87.8)$ & $46(95.8)$ & 0.10 \\
\hline $\begin{array}{l}\text { Stays with } \\
\text { family }\end{array}$ & $41(85.4)$ & $45(93.8)$ & 0.18 \\
\hline $\begin{array}{l}\text { Domestic } \\
\text { helper }\end{array}$ & 15 (31.9) & $10(21.3)$ & 0.24 \\
\hline $\begin{array}{l}\text { Currently } \\
\text { employed }\end{array}$ & $11(22.4)$ & $13(27.1)$ & 0.60 \\
\hline $\begin{array}{l}\geq 5 \text { chronic } \\
\text { medications }\end{array}$ & $15(31.3)$ & $6(12.8)$ & 0.03 \\
\hline Chronic pain & $25(51.0)$ & $8(16.7)$ & $<0.001$ \\
\hline Depression & $3(6.1)$ & $0(0)$ & 0.24 \\
\hline $\begin{array}{l}\text { bADL } \\
\text { restriction }\end{array}$ & $6(12.8)$ & $1(2.1)$ & 0.06 \\
\hline
\end{tabular}

Categorical variables expressed as no. (\%) were compared using Pearson chisquare test or Fisher's exact test, as appropriate. ${ }^{*}$ Continuous variables expressed as median (interquartile range 25 th-75th percentile) were compared using MannWhitney $U$ test. bADL: basic activities of daily living (bathing, toileting, dressing, eating, transferring and mobility)
Table IV. Bivariate and multivariable analysis for factors associated with non-robustness.

\begin{tabular}{|lll|}
\hline Factor & $\begin{array}{l}\text { Unadjusted OR } \\
(95 \% \mathbf{C I})\end{array}$ & $\begin{array}{l}\text { Adjusted OR } \\
(\mathbf{9 5 \%} \mathbf{C I})\end{array}$ \\
\hline $\begin{array}{l}\text { Absence of a living } \\
\text { married spouse }\end{array}$ & $4.20(1.49-11.83)$ & $3.64(1.22-10.88)$ \\
\hline Formal education & $0.34(0.13-0.84)$ & - \\
\hline $\begin{array}{l}\geq 5 \text { chronic } \\
\text { medications }\end{array}$ & $3.82(1.26-11.59)$ & - \\
\hline Chronic pain & $5.21(2.03-13.38)$ & $4.48(1.68-11.92)$ \\
\hline
\end{tabular}

Binary logistic regression analysis (stepwise method) was used to calculate OR and $95 \% \mathrm{Cl}$ for factors associated with outcomes. Covariates were chosen if $\mathrm{p} \leq 0.05$ on bivariate analysis. $\mathrm{Cl}$ : confidence interval; OR: odds ratio

\section{DISCUSSION}

The study confirmed that frailty and non-robustness were common among older adults who consulted at a general practice clinic. Frailty was present in about $12 \%$ of older adults at our general practice clinic. In contrast, among other local cohorts, the prevalence of frailty was higher among hospitalised older adults (50\%) and lower in the general population (6.2\%), using the same FRAIL scale. ${ }^{(5,7)}$ In our study, chronic pain and the absence of a living spouse were independently associated with non-robustness. Recent international studies have found similar associations between chronic pain and frailty. ${ }^{(29-31)}$ Although an interacting mediator may be present, Tian et al showed that the association persisted after mediation analysis for depression. ${ }^{(32)}$

The association between marital status and frailty syndrome has not been evaluated locally. A longitudinal study involving 515 community-dwelling adults aged 65 years and above in Brazil identified an inverse relationship between having a living spouse and frailty. ${ }^{(33)}$ It is possible that the lack of companionship may contribute to poorer health behaviours that lead to the onset of frailty syndrome. ${ }^{(34)}$

The limitations of the present study included recall bias, as some questions in the FRAIL scale, such as chronic disease history and weight loss, were self-reported. Also, inter- and intrainterviewer variability could lead to potential bias. We attempted to minimise this with standardised training of the two interviewers involved. The association between cognitive impairment and frailty syndrome was not investigated due to the inherent nature of a telephone interview-based study. Our small sample size may also have limited the power to detect a statistically significant difference in factors that are weakly associated with frailty. Findings from a single-centre general practice clinic may not be generalisable to other cohorts with different socioeconomic demographics.

Despite these limitations, this study had a few strengths. It highlighted that frailty and pre-frailty were common among older individuals at a primary care clinic in Singapore. It also identified clinical and socio-economic factors that can alert the busy general practitioner to consider a formal frailty assessment and formulate management plans to treat or reverse frailty states. 


\section{ACKNOWLEDGEMENT}

We would like to acknowledge Dr Cynthia Lim, Senior Consultant, Department of Renal Medicine, Singapore General Hospital, for support with statistical analysis.

\section{REFERENCES}

1. Department of Statistics, Singapore. Elderly, Youth and Gender Profile. Available at: https://www.singstat.gov.sg/find-data/search-by-theme/population/elderlyyouth-and-gender-profile/latest-data. Accessed January 14, 2020

2. Vermeiren S, Vella-Azzopardi R, Beckwée D, et al. Frailty and the prediction of negative health outcomes: a meta-analysis. J Am Med Dir Assoc 2016; 17:1163. e1-e17.

3. Espinoza SE, Jung I, Hazuda H. Frailty transitions in the San Antonio Longitudinal Study of Aging. J Am Geriatr Soc 2012; 60:652-60.

4. Kojima G, Taniguchi Y, Iliffe S, Jivraj S, Walters K. Transitions between frailty states among community-dwelling older people: a systematic review and metaanalysis. Ageing Res Rev 2019; 50:81-8.

5. Merchant RA, Chen MZ, Tan LWL, et al. Singapore Healthy Older People Everyday (HOPE) Study: prevalence of frailty and associated factors in older adults. J Am Med Dir Assoc 2017; 18:734.e9-e14.

6. Vaingankar JA, Chong SA, Abdin E, et al. Prevalence of frailty and its association with sociodemographic and clinical characteristics, and resource utilization in a population of Singaporean older adults. Geriatr Gerontol Int 2017; 17:1444-54.

7. Chong E, Ho E, Baldevarona-Llego J, et al. Frailty and risk of adverse outcomes in hospitalized older adults: a comparison of different frailty measures. J Am Med Dir Assoc 2017; 18:638.e7-e11.

8. Setiati S, Laksmi PW, Aryana IGPS, et al. Frailty state among Indonesian elderly: prevalence, associated factors, and frailty state transition. BMC Geriatr 2019 19:182.

9. Kendhapedi KK, Devasenapathy N. Prevalence and factors associated with frailty among community-dwelling older people in rural Thanjavur district of South India: a cross-sectional study. BMJ Open 2019; 9:e032904.

10. Lau DT, Mercaldo ND, Shega JW, Rademaker A, Weintraub S. Functional decline associated with polypharmacy and potentially inappropriate medications in community-dwelling older adults with dementia. Am J Alzheimers Dis Other Demen 2011; 26:606-15.

11. Fraser SD, Roderick PJ, May CR, et al. The burden of comorbidity in people with chronic kidney disease stage 3: a cohort study. BMC Nephrol 2015; 16:193.

12. Lundy $E$, McMullan D, McShane $P$, et al. Polypharmacy and drug omissions across hospices in Northern Ireland. J Palliat Med 2013; 16:1446-9.

13. Sav A, Salehi A, Mair FS, McMillan SS. Measuring the burden of treatment for chronic disease: implications of a scoping review of the literature. BMC Med Res Methodol 2017; 17:140.

14. Nugraha B, Gutenbrunner C, Barke A, et al. The IASP classification of chronic pain for ICD-11: functioning properties of chronic pain. Pain 2019; 160:88-94.
15. Buta BJ, Walston JD, Godino JG, et al. Frailty assessment instruments: systematic characterization of the uses and contexts of highly-cited instruments. Ageing Res Rev 2016; 26:53-61.

16. Jung HW, Yoo HJ, Park SY, et al. The Korean version of the FRAIL scale: clinical feasibility and validity of assessing the frailty status of Korean elderly. Korean J Intern Med 2016; 31:594-600.

17. Rubenstein LZ, Stuck AE, Siu AL, Wieland D. Impacts of geriatric evaluation and management programs on defined outcomes: overview of the evidence. J Am Geriatr Soc 1991; 39(9 Pt 2):8S-16S; discussion 7S-8S.

18. Kojima G, Liljas AEM, Iliffe S. Frailty syndrome: implications and challenges for health care policy. Risk Manag Healthc Policy 2019; 12:23-30.

19. Abellan van Kan G, Rolland Y, Bergman H, et al. The I.A.N.A Task Force on frailty assessment of older people in clinical practice. J Nutr Health Aging 2008; 12:29-37.

20. Aprahamian I, Cezar NOC, Izbicki R, et al. Screening for frailty with the FRAIL Scale: a comparison with the phenotype criteria. J Am Med Dir Assoc 2017; 18:592-6.

21. Lopez D, Flicker L, Dobson A. Validation of the frail scale in a cohort of older Australian women. J Am Geriatr Soc 2012; 60:171-3.

22. Morley JE, Malmstrom TK, Miller DK. A simple frailty questionnaire (FRAIL) predicts outcomes in middle aged African Americans. J Nutr Health Aging 2012; 16:601-8.

23. Woo J, Yu R, Wong M, et al. Frailty screening in the community using the FRAIL Scale. J Am Med Dir Assoc 2015; 16:412-9.

24. Dong L, Qiao X, Tian X, et al. Cross-cultural adaptation and validation of the FRAIL Scale in Chinese community-dwelling older adults. J Am Med Dir Assoc 2018; 19:12-7.

25. Rockwood K, Mitnitski A. Frailty in relation to the accumulation of deficits. J Gerontol A Biol Sci Med Sci 2007; 62:722-7.

26. Fried LP, Tangen CM, Walston J, et al. Frailty in older adults: evidence for a phenotype. J Gerontol A Biol Sci Med Sci 2001; 56:M146-56.

27. Cawthon PM, Marshall LM, Michael Y, et al. Frailty in older men: prevalence, progression, and relationship with mortality. J Am Geriatr Soc 2007; 55:1216-23.

28. Malmstrom TK, Miller DK, Morley JE. A comparison of four frailty models. J Am Geriatr Soc 2014; 62:721-6.

29. Shega JW, Dale W, Andrew M, et al. Persistent pain and frailty: a case for homeostenosis. J Am Geriatr Soc 2012; 60:113-7.

30. Wade KF, Lee DM, McBeth J, et al. Chronic widespread pain is associated with worsening frailty in European men. Age Ageing 2016; 45:268-74.

31. Blyth FM, Rochat $S$, Cumming RG, et al. Pain, frailty and comorbidity on older men: the CHAMP study. Pain 2008; 140:224-30.

32. Tian X, Wang C, Qiao X et al. Association between pain and frailty among Chinese community-dwelling older adults: depression as a mediator and its interaction with pain. Pain 2018; 159:306-13.

33. Fhon JRS, Rodrigues RAP, Santos JLF, et al. Factors associated with frailty in older adults: a longitudinal study. Rev Saude Publica 2018; 52:74.

34. Watt RG, Heilmann A, Sabbah W, et al. Social relationships and health related behaviors among older US adults. BMC Public Health 2014; 14:533. 